https://doi.org/10.24201/aap.2021.324

INFORME

\title{
Indonesia 2020: inquietud por la democracia mientras la covid-19 azota al país
}

\section{Indonesia 2020: Concern for Democracy and Covid-19 Ravages the Country}

\author{
CHRIS LUNDRY \\ https://orcid.org/0000-0002-7160-7534 \\ El Colegio de México, A.C., México
}

Recepción: 26 de octubre de 2020

Aceptación: 13 de noviembre de 2020

Resumen: Algunos observadores apuntan señales de autoritarismo creciente en la segunda administración de Jokowi, que solía ser populista, incluyendo signos de militarización creciente. La respuesta de Indonesia ante la covid-19 ha sido muy criticada y ha posicionado a Anies Baswedan, el alcalde de Yakarta, como un contendiente serio para las elecciones presidenciales de 2024. Se aprobaron varias leyes controvertidas que desencadenaron fuertes críticas de diversos grupos, así como numerosas manifestaciones callejeras por todo el país. El descontento prevalece en Papúa Occidental después de los enfrentamientos violentos que hubo en Java y en otros sitios el año pasado, mientras que docenas de papúes permanecen en la cárcel. China y el Mar de la China Meridional siguen siendo una amenaza para la política exterior indonesia, aunque los resultados de la elección de Estados Unidos pueden afectarla en el futuro.

Palabras clave: Indonesia; Papúa Occidental; covid-19; democracia; política exterior. 
Abstract: Observers are pointing to signs of increasing authoritarianism in the once-populist Jokowi's second administration, including troubling signs of increased militarization. Indonesia's Covid-19 response has been widely criticized, and has positioned Anies Baswegan, the Mayor of Jakarta, as a serious contender for the 2024 presidential elections. Several controversial laws were passed which set off widespread condemnation from a variety of groups as well as widespread street demonstrations throughout the country. Unrest continues in West Papua following violent clashes in Java and elsewhere last year, and dozens of Papuans remain jailed. China and the South China Sea continue to loom large in Indonesian foreign policy, although the results of the election in the USA may affect future policy.

Keywords: Indonesia; West Papua; Covid-19; Democracy; Foreign Policy.

Aunque la reelección de Joko Widodo (Jokowi) en 2019 se aclamó como un rechazo a las tendencias antidemocráticas más evidentes de su oponente, Prabowo Subianto, el año 2020 ha planteado interrogantes sobre el compromiso de Jokowi con la democracia y ha causado que algunos críticos adviertan de un posible regreso al autoritarismo. Algunos percibieron en el nombramiento de Prabowo como titular del Ministerio de la Defensa una manifestación de la filosofía "mantén cerca a tus amigos y más cerca a tus enemigos", pero en realidad parece tratarse simplemente de una continuación de la cooptación de las élites tradicionales y militares, tanto para evitar las críticas como para crear una coalición mayoritaria indiscutida en el Parlamento. Las maniobras para ampliar las funciones de los militares, las leyes diseñadas para reducir la independencia de la Comisión para la Erradicación de la Corrupción (CEC) (Komisi Pemberantasan Korupsi, KPK) y para beneficiar a las empresas a expensas del medio ambiente y de los trabajadores, la aprehensión de manifestantes pacíficos y la creciente dificultad que enfrentan la prensa y los investigadores extranjeros para tener acceso a Indonesia son signos preocupantes. En octubre, la aprobación de una iniciativa de ley general diseñada para contribuir a la recuperación económica, pero también para optimizar la inversión, llevó a extensas manifestaciones en las calles. Hubo repercusiones continuas de las manifestaciones de Papúa Occidental, que se desencadenaron después de las provocaciones y los ataques racistas en Java Oriental en agosto de 2019, las cuales dieron lugar a arrestos de manifestantes y periodistas por igual. Además, 2020 fue testigo de la 
creación de Papuan Lives Matter [Las vidas de los papúes importan], inspirado en el movimiento Black Lives Matter de Estados Unidos en un esfuerzo por dar a conocer la situación desesperada de los papúes occidentales en Indonesia.

El primer día de 2020 hubo devastadoras inundaciones en Yakarta y Java Occidental que se repitieron a lo largo del año. El reportaje más trascendente en Indonesia durante 2020, como en prácticamente el resto del mundo, fue la pandemia causada por el coronavirus. Indonesia fue muy criticada por su respuesta ineficiente y tardía, que causó el número más elevado de muertes en todo el sureste asiático, al tiempo que produjo rumores, conspiraciones y remedios mágicos.

Aunque la próxima elección presidencial está programada para 2024, ya hay discusiones sobre quién será un contendiente serio, dado que los límites a los mandatos impiden que Jokowi vuelva a presentarse a la contienda. Anies Baswedan, el actual alcalde de Yakarta y crítico emergente de Jokowi, es considerado uno de los candidatos que van a la cabeza en una etapa temprana. Sin embargo, también hay rumores de que Jokowi, que cuenta con una gran coalición mayoritaria en el Parlamento, podría tratar de ampliar su administración a siete años o más, o bien, intentar eliminar los límites temporales para poder competir de nuevo. Valdrá la pena vigilar estas áreas de la política indonesia.

\section{COVID-19: UNA RESPUESTA SIN COORDINACIÓN Y CONTAGIOS SIN CONTROL}

Al igual que en el resto del mundo, la covid-19 fue el tema dominante en Indonesia en 2020. A mediados de octubre, el número de muertos en Indonesia se elevaba a 12 500, con más de 353000 casos confirmados. En comparación con otros países con grandes poblaciones como Brasil, India y Estados Unidos, Indonesia, que es el cuarto país más poblado, no parece estar tan mal. Sin embargo, en comparación con el epicentro de la enfermedad, China, o con sus vecinos del sureste asiático, la situación de Indonesia es mala.

Gran parte de la culpa, como en otros sitios donde el virus proliferó libremente, puede atribuirse al presidente y a los líderes de alto nivel de Indonesia. Una respuesta lenta por parte del Jokowi, quien titubeó en cuanto a la eficacia de las medidas estrictas y la capacidad para 
procurar su cumplimiento, permitió que el virus se arraigara en Yakarta y otras ciudades grandes antes de propagarse en otros lugares. Esto se complicó por las afirmaciones de líderes importantes, así como de varias figuras públicas y clérigos, sobre "curas milagro" o conductas que podían evitar los contagios. El vicepresidente de Indonesia, Mar'uf Amin, se encuentra entre ellos. El 3 de marzo, durante una visita a la isla de Lombok, afirmó que ésta ya contaba con un elemento que podía prevenir la covid, "que es la leche de caballo bronco" (CNN Indonesia 2020). En julio, mucho después de que el virus ya se había instalado en el país, el ministro de Agricultura, Syahrul Yasin Limpo, pregonó las propiedades curativas de los collares de hojas de eucalipto, lo que causó una enérgica condena por parte de los científicos (Wartakotalive.com 2020). El gobernador de Bali, I Wayan Koster, quizá deseoso de unirse a la tendencia de las curas milagro, afirmó que el vino de palma (arak) tenía propiedades curativas (Detiktravel 2020). Además, algunos rumores, como el que afirmaba que los termómetros infrarrojos usados para tomar la temperatura a las personas podían causar daño cerebral, obstaculizaron las medidas preventivas reales.

Antes de que se anunciara el primer caso confirmado de covid-19, muchos sospechaban que el virus ya había estado en Indonesia durante semanas o incluso meses, sobre todo en destinos turísticos como Bali o Jogjakarta, donde hay mucho tráfico de visitantes chinos. El ministro de Salud de Indonesia, Terawan Agus Putranto, quien tardó más que sus vecinos en implementar el uso de pruebas, afirmó que el virus era poco más grave que la influenza. Algunos líderes musulmanes afirmaron que el niqab, un velo que cubre el rostro, podía evitar el contagio de covid-19. En Lombok Central, el Bupati (regente) Moh Suhaili Fadhil Thohir anunció que se solicitaría a las servidoras públicas musulmanas que portaran el niqab para reducir el contagio de covid (The Jakarta Post, 2020). El uso del niqab es relativamente raro en Indonesia, pero ha ido en aumento, lo que algunos consideran como prueba del ascenso del islamismo. Además, no hay evidencia científica de que el uso del niqab pueda ayudar a evitar los contagios. Por otro lado, se ha culpado a algunas prácticas musulmanas de facilitar la proliferación del virus. Por ejemplo, los rituales funerarios que incluyen limpiar, tocar y amortajar a los cadáveres antes de su entierro han causado la difusión de covid-19 (Tri Bayu Purnama et al. 2020). 
No obstante, al parecer, algunos esfuerzos "no tradicionales" para controlar al coronavirus han funcionado. En algunos lugares, voluntarios se han disfrazado de pocong (fantasmas) o con túnicas blancas y pintura facial para asustar a la gente en interiores (Budi Purwanto 2020). En otros sitios se ha forzado a quienes han desobedecido las normas de la cuarentena a pasar la noche en una casa "embrujada" (Mahfira Putra Maulani 2020). En algunas ocasiones se ha obligado a personas aprehendidas por no tomar precauciones a enterrar a víctimas mortales de covid-19 (SBS New, 2020).

En un inicio, la administración de Jokowi puso en tela de juicio la seriedad de la enfermedad y la entrada del virus a Indonesia; ahí, tardó en implementar el distanciamiento social, el uso de cubrebocas y otras medidas por miedo a las consecuencias económicas; también tardó en aplicar pruebas, iniciar el rastreo de contactos y otras reglas que pudieron haber mitigado el contagio de covid-19. Parte de la responsabilidad recae en la cultura de toma de decisiones de alto nivel en el gobierno de Jokowi, así como en la naturaleza de la oposición política entre el alcalde de Yakarta, Anies Baswedan, y el presidente Jokowi.

Según un análisis de Alexander Arifianto, fellow de investigación en la Facultad de Estudios Internacionales S. Rajaratnam (RSIS, por sus siglas en inglés) de la Universidad Tecnológica Nanyang de Singapur, "la respuesta apática y tibia de Indonesia a la pandemia se debe a su legado histórico, que afecta la forma en que los creadores de política indonesios formulan las medidas para mitigar la crisis sanitaria. Esto incluye una burocracia incompetente pero aislada que no valora los consejos políticos de expertos externos y un acuerdo de compartición del poder entre los miembros de su élite política que privilegia los cálculos políticos a corto plazo por encima de las acciones coherentes, coordinadas y decisivas" (Busby 2020). El problema se debe en parte a la falta de confianza en el ministro de Salud de Jokowi, Terawan Agus Putranto, a quien se censuró en 2018 y a quien la Asociación Médica Indonesia (Ikatan Dokter Indonesia, IDI) retiró su acreditación debido a violaciones, por promover terapias sin beneficios comprobados. Dicha organización se opuso al nombramiento de Putranto como ministro de Salud en 2019. Quienes critican la respuesta de Jokowi ante la covid-19 afirman que en un gobierno lleno de militares y de políticos proempresa hay una escasez de profesionales de la salud confiables. Con el nombramiento de un gabinete de élites militares orientadas a los negocios, los intereses de éstas se volvieron 
primordiales, en lugar de las acciones orientadas hacia la salud pública y la mitigación de la crisis.

Además, la respuesta a la enfermedad se politizó debido a la animosidad entre el alcalde Anies y el presidente Jokowi. Anies compitió contra uno de los acólitos de Jokowi, Basuki Tjahaja Purnama (Ahok), en una aguerrida campaña por la elección a gobernador de Yakarta en 2017 y ganó (más adelante se proporcionan más detalles). En un inicio, Anies se negaba a criticar abiertamente a Jokowi, pero más adelante cambió de estrategia y lo culpó por su respuesta a la crisis de covid-19 (y por las inundaciones de Yakarta y de Java Occidental); asimismo, y recomendó medidas más fuertes de distanciamiento social, que en retrospectiva fueron más efectivas. Sin embargo, ofendido por las críticas y reacio a admitir sus errores, Jokowi siguió evitando implementar medidas, lo que generó un aumento en el número de contagios en Yakarta y en otros sitios. Un elemento que se discutió fue la posibilidad de cancelar el mudik, el regreso masivo a casa de personas que trabajan en Yakarta y en otras zonas para celebrar el Eid al Fitr, el fin del mes de ayuno del Ramadán. En un inicio, Jokowi dudó de la factibilidad de emitir una orden de esta naturaleza, y para cuando se anunció la cancelación del mudik, con el apoyo de las mayores organizaciones musulmanas de Indonesia, Nahdlatul Ulama (NU), Muhammadiyah y el Consejo de Ulemas de Indonesia (Majelis Ulama Indonesia, MUI), millones de personas ya habían iniciado o terminado su viaje a casa, mientras que otros simplemente ignoraron la prohibición. Una respuesta más temprana, coordinada y coherente hubiera evitado este resultado. Por su parte, las organizaciones sí declararon que el mudik debía cancelarse en el contexto de la lucha contra la covid-19. Además han difundido información e implementado medidas, al igual que las mezquitas y los pesantren (internados islámicos) en toda Indonesia. NU también declaró que, con base en la exégesis coránica, quienes fallezcan a causa de la covid-19 se considerarán mártires (Woodward 2020).

Si bien el miedo a una catástrofe económica entre las élites de Yakarta quizá no fue la mejor base para plantear una respuesta, la economía sí se ha visto muy afectada por la crisis sanitaria. Tras 20 años de crecimiento económico sostenido, en 2020 se vio una marcada desaceleración. Los efectos económicos han cambiado las predicciones de crecimiento, de alrededor de 5\% al inicio del año, hasta incluso $0.5 \%$. Como ocurre en otras 
partes del mundo, muchas industrias, como la hotelera, la restaurantera y la turística, han sufrido grandes pérdidas. Bali, que obtiene gran parte de su presupuesto del turismo nacional y extranjero, se ha visto particularmente afectada. Por ejemplo, el número de turistas chinos cayó de 113646 en enero a sólo 4820 en febrero de 2020 (Imam Rosidin 2020). Aún queda por verse el grado y la longevidad del daño económico causado por la covid-19, que depende de qué tan pronto pueda aplicarse una vacuna, entre otros factores. No obstante, los partidarios de Jokowi mencionan cifras económicas aún peores para los vecinos de Indonesia en el sureste asiático, lo que ejemplifica el argumento planteado de que quizá sea aceptable que haya algunas muertes con tal de salvar la economía.

Indonesia ha tenido un desempeño mucho peor que sus vecinos en un aspecto de la covid-19: la mortalidad infantil. Varios factores contribuyen a la muerte de los niños por esta enfermedad, entre ellos la falta de crecimiento, la obesidad y el tabaquismo (Walden y Souisa 2020). Además, la aplicación de pruebas es extremadamente baja en Indonesia en comparación con otros países, por lo que es imposible saber cuál es el verdadero saldo del virus. Cuando se analizan los problemas de Indonesia en el manejo de esta enfermedad, también debe tenerse en cuenta la pobreza del país y la debilidad de su infraestructura médica. Sin embargo, un efecto concreto de la vida con la covid-19 en Indonesia es el deterioro de la confianza de la población en el gobierno y del apoyo a la democracia, debido a su reacción ante la pandemia (Honna 2020). A pesar de la responsabilidad que Jokowi debe asumir por esta respuesta, su índice de aprobación es cercano al que tenía al inicio de la crisis.

\section{POLÍTICA INTERIOR Y LA ECONOMÍA:}

\section{TEMOR A UN RETROCESO AL AUTORITARISMO}

Algunos observadores de la política indonesia se han alarmado por la presencia de signos de un "regreso al autoritarismo", o un alejamiento de la democracia creciente, para volver a algunas de las prácticas del régimen autoritario del Nuevo Orden de Suharto. Estas inquietudes no son infundadas, e Indonesia, a la que se ha elogiado por ser una de las naciones más democráticas del sureste asiático después de que Filipinas y Tailandia vivieran sus propias regresiones autoritarias en los últimos años, bien podría tomar esa dirección. Con el ascenso del populismo en el mundo, con ejemplos desde India hasta Brasil y Estados Unidos, 
y la democracia bajo asedio en la región del sureste de Asia, ¿podría Indonesia regresar a alguna forma de régimen populista apoyado por el ejército?

En el ámbito de las instituciones, Jokowi nombra cada vez más generales retirados y generales de la policía en puestos clave de su gobierno. Algunos generales del ejército en retiro ahora ocupan puestos, como el de ministro de Asuntos Religiosos (Fahlur Razi) y el de ministro coordinador de Asuntos Marítimos (Luhut Pandjaitan). En julio, Fahlur causó preocupación cuando propuso un plan para involucrar al ejército en labores dirigidas a mantener la armonía entre las religiones (Ihsan Ali Fauzi 2020). Además, hay generales retirados de la policía que aún ocupan puestos importantes, como el ministro de Interiores (Tito Karnavian) y el director del Servicio Nacional de Inteligencia (Budi Gunawan), así como jefes de otras dependencias importantes del gobierno indonesio. De acuerdo con Arifianto, "se culpa al dominio de estos oficiales retirados en esta administración de las medidas 'autoritarias' que se han instaurado en el último año, tales como la ley aprobada en agosto de 2019 que restringe severamente las actividades de académicos e investigadores extranjeros en Indonesia" (Parameswaran 2020). El ministro de Salud, a quien se mencionó anteriormente, Terawan Agus Putranto, también solía ser médico militar.

Además de los nombramientos de generales en puestos de poder de la administración - algo en lo cual Indonesia tiene una larga trayectoria que se remonta al Nuevo Orden de Suharto - la institución militar misma intenta hacerse de más espacio, lo que alimenta los temores de un posible retroceso de la democracia. La covid-19 y otros factores han brindado un espacio para que el ejército se reafirme o fortalezca su posición en diversas áreas. Según un reporte que apareció en el Asia-Pacific Journal [Revista Asia-Pacífico], el ejército ha estado creando nuevos comandos y puestos para que los ocupen sus líderes, en un intento por recuperar el espacio que perdieron durante las fases iniciales de la democratización. Algunas áreas en las que el ejército se está reafirmando incluyen la fuerza de respuesta a la covid-19, que encabeza el teniente general Doni Monardo, el debate sobre los Pancasila (supra) y un aumento de su función en tareas de contraterrorismo (Honna 2020). El antagonismo entre el ejército y la policía se vio exacerbado cuando ambas fuerzas se dividieron en 2002, y posteriormente en 2003, con la creación del escuadrón antiterrorismo Densus 88, encabezado por la policía; así que el ejército ha presionado tras bambalinas para ampliar sus funciones. 
Para aquellos que tienen la edad suficiente para recordar la profunda militarización de la sociedad indonesia bajo el nuevo orden de Suharto, estas maniobras no son buena señal. Por ejemplo, los críticos argumentan que un enfoque de salud pública para combatir la covid-19 sería mucho más adecuado que el abordaje basado en la seguridad.

Además, la policía también está aumentando su visibilidad y sus funciones, tomando como pretexto la covid-19 y el descontento de la población civil. Una de las formas en que lo hace, que anunciara en abril el jefe de la Policía Nacional, Idham Azis, es la creación de “ciberpatrullas" con el fin de monitorear las redes sociales y evitar la difusión de información falsa y "engaños" - pero también de identificar a las personas que pueden estar usando estas redes para difamar al presidente. Ambos delitos se castigan con cárcel. Las "ciberpatrullas" comenzaron a operar tras la firma de la iniciativa de ley general de economía en el mes de octubre, cuando estallaron las protestas. Un documento interno de la policía que se filtró señalaba métodos para controlar las manifestaciones y para montar una contracampaña en línea (Timmerman 2020).

Los críticos afirman que la campaña de reelección de Jokowi en 2019 había cambiado su enfoque. Si bien el presidente es afecto a emprender obras, como carreteras de peaje (elementos que la mayoría de los indonesios aprecian mucho y que aumentan su popularidad), su segunda campaña se basó en los fondos que donaron las élites, esencialmente los oligarcas arraigados en la cúspide de la pirámide económica del país. Uno de sus proyectos faro, quizá el más ambicioso, es su propuesta de trasladar la capital nacional a Penajam Paser, Kalimantan oriental, que sigue vigente y se llevará a cabo a más tardar en 2024. Sin embargo, debido a la desaceleración económica asociada a la covid-19, algunos expertos consideran que el plan podría retrasarse o incluso suspenderse por completo.

En 2019 el presidente nombró a su oponente político, Prabowo Subianto, como ministro de la Defensa, lo que causó estupor e inspiró a la gente a susurrar una versión del refrán "mantén cerca a tus amigos y más cerca a tus enemigos". Sin embargo, cada vez resulta más evidente que Prabowo, miembro de la oligarquía, simplemente está facilitando que entable más contactos con los grandes capitales. Además ha permitido a Jokowi recibir el apoyo de una coalición que conforma alrededor de 75\% del Parlamento. El alejamiento de Jokowi del "pueblo" — - y, en efecto, de la democracia popular — ha causado en muchos el 
temor de que Indonesia anteponga el dinero a la justicia (The Economist 2020). Asimismo, se rumora que Jokowi podría estar considerando sustituir a su vicepresidente, Mar'uf Amin, quien se cree sirvió para mejorar las credenciales islámicas del candidato durante la campaña electoral, pero ya no es de utilidad, según algunos (Rosyid 2020).

La aprobación en 2020 de dos leyes, la de minería y la general, apoyan esta interpretación. Si bien en 2019 fracasó una versión de la ley de minería, el gobierno aprobó una similar diseñada para alentar la inversión nacional y extranjera en el sector minero. Su objetivo es optimizar los procesos, así como crear incentivos y dar seguridad a los inversionistas de la industria. Además, la ley elimina los límites al tamaño de las operaciones y permite que los contratos se prorroguen automáticamente hasta por 20 años. Los críticos señalan que la ley se escribió básicamente para complacer al sector minero, sin preocuparse por el impacto sobre el medio ambiente y los seres humanos, pues provocará que grandes extensiones se deforesten y se contaminen. El año pasado fracasó la iniciativa frente a manifestaciones callejeras de dimensiones considerables, y, según los críticos, el gobierno la aprobó este año aprovechando las medidas de distanciamiento social que acotaron la respuesta de la población.

Por otra parte, en octubre se aprobó una ley económica "ómnibus" con el objetivo de reducir los trámites burocráticos, así como las prestaciones laborales. Los críticos del régimen señalan que socavar las prestaciones de los trabajadores en medio de una enorme desaceleración económica causada por la pandemia hace que la administración de Jokowi parezca no estar en contacto con la realidad. Jokowi se mostró como amigo de la gente común, pero The Economist, que suele ser conservador y proempresa, afirma que en fechas recientes ha ido cambiando el rumbo para apoyar a las grandes empresas a expensas del pueblo (The Economist 2020).

Aunque la iniciativa gozó de gran apoyo en el Parlamento, con sólo dos partidos opositores, su aprobación provocó manifestaciones callejeras en toda Indonesia. Trabajadores y sindicatos organizaron protestas para condenar abiertamente el deterioro de la protección a los trabajadores. A su vez, a ellos se unieron los ambientalistas, que afirman que la nueva ley aniquila las disposiciones que protegen el medio ambiente para favorecer a la industria. Específicamente, esta ley disminuirá la protección al bosque tropical primario 
que aún queda en Indonesia y podría provocar una extensa deforestación. Ello contradice directamente el "crecimiento verde", que Jokowi decía apoyar, y empujó a algunos inversionistas internacionales — con carteras por un total de $\$ 4.1$ billones de dólares - a advertir que Indonesia no estaba cumpliendo con las mejores prácticas ambientales (Reuters Staff 2020).

El sector del aceite de palma, que representa 2\% del PIB del país, se encuentra especialmente en riesgo. La Unión Europea y el Reino Unido han reaccionado a la ley con un análisis de sus requisitos ambientales para el aceite de palma importado. Del mismo modo, varias empresas transnacionales, como Nestlé, McDonald's, Unilever y Tesco, enviaron una declaración al gobierno de Reino Unido para que amplíe su legislación contra la deforestación en las importaciones, de manera que incluya la deforestación legal y la ilegal. Esto podría ser un desastre para Indonesia. Como escribió Phelim Kine en The Diplomat, "una omisión en este sentido bien podría condenar a Indonesia a convertirse en el Brasil de Asia - un país que comercia deliberadamente los tesoros de su medio ambiente por las cenizas y la bruma del crecimiento económico autodestructivo a corto plazo" (Kine 2020).

En enero iniciaron las manifestaciones en contra de la iniciativa, pero en octubre, después de su aprobación y, a pesar de que el gobierno indonesio cooptara a influencers de las redes sociales y a celebridades para que la promovieran, se desencadenaron las protestas en todo el país, que continúan al momento en que se escribe el presente artículo. Los manifestantes también utilizaron las redes sociales, se burlaron de quienes apoyaban la iniciativa y acuñaron el término "cilaka", que es un anagrama del nombre de la ley pero tiene un sonido similar a celaka, vocablo indonesio que denota tristeza. La policía ha aprehendido a cientos de manifestantes en todo el país, entre acusaciones de brutalidad policiaca y represión de la libertad de expresión.

En el contexto de las protestas masivas, algunos también cuestionan la motivación de aquellos que las fomentan, entre los que se incluyen grupos islamistas radicales, mientras otros incluso llaman a la renuncia de Jokowi. En la Yakarta de Anies, el apoyo a los grupos islamistas, como el Frente de Defensores Islámicos — un grupo que apoyó a Anies en la elección pero cuenta entre sus miembros a personas acusadas de delitos graves, que tienen antecedentes en pandillas durante el Nuevo Orden - y una coalición de otras agrupaciones 
que apoyaron a Anies contra Ahok, han hecho que algunos se pregunten si las manifestaciones tienen motivaciones políticas subyacentes. En la política indonesia, como siempre, las problemáticas se enturbian muy pronto.

Es cierto que Anies está aprovechando la oportunidad para criticar a Jokowi. El primero ocupa actualmente el puesto que el segundo tenía antes de convertirse en presidente, gobernador de Yakarta, que quizá puede verse como un trampolín hacia la presidencia. Anies tomó el poder después de que se acusara de blasfemia a su oponente, Basuki Tjahaja Purnama (Ahok), en la elección a la gubernatura de 2017. Se consideraba que Ahok era aliado de Jokowi, pero en un principio Anies no enfatizó la animosidad ni sus diferencias con Jokowi. Eso cambió este año, cuando comenzó a criticar abiertamente la reacción de Jokowi ante la inundación de Yakarta en enero, y más adelante, durante las etapas iniciales de la crisis de covid-19 en Indonesia, acentuó su desaprobación. Jokowi se oponía a los cierres masivos y Anies lo contradecía muy públicamente. Anies parece preocuparse por los temas ante los que Jokowi parece distante y emplea datos para respaldar sus dichos. Definitivamente tiene aspiraciones a la presidencia en 2024, cuando los límites de los mandatos evitarán que Jokowi compita de nuevo. Presentarse hoy como opuesto a Jokowi, su legislación impopular y lo que se percibe como su fracaso en el control de la covid-19 sería un buen primer paso hacia la declaración de su candidatura para 2024. Sin embargo, no debe considerarse inevitable la salida de Jokowi ese año. Es posible que el popular Jokowi, con el apoyo de su gran mayoría en el Parlamento, intente ampliar la duración de los mandatos presidenciales a siete años, o quizá modificar la restricción a sus límites para que sean tres, en lugar de los dos que se aceptan actualmente. Sin embargo, estas posibilidades permanecen en el terreno de la especulación y el rumor, y Jokowi no ha indicado públicamente que apoyaría ninguna de ellas.

Hay una tercera iniciativa que está causando revuelo en la política indonesia. Con la intención original de sanar las divisiones que causó la elección de 2019, en la que, como nunca, la religión se convirtió en un factor de desunión, el Partido Democrático Indonesio de Lucha (Partai Demokrasi Indonesia Perjuangan, PDI-P) planteó una propuesta para revisar los Pancasila, los cinco principios sobre los que está fundado el Estado indonesio, frente al ascenso de la intolerancia religiosa y el islam derechista. La propuesta, que buscaba reducir 
la retórica religiosa decisiva, volvió a enfatizar la naturaleza secular del Estado y el respeto a los principios científicos. Organizaciones religiosas importantes, tales como NU, Muhammadiyah y el MUI, expresaron su oposición a la iniciativa, afirmando que eliminaría la religión de la vida pública (Abdul Rochim 2020). El ejército la había apoyado, quizá por ver en ella otra oportunidad de inyectarse en la política indonesia, pero quizá también reflejando la división tradicional entre sí mismo y los grupos religiosos, que se remonta a la fundación de la nación. La iniciativa se suspendió en 2020, pero sigue siendo una posibilidad hasta la sesión legislativa de 2024.

Además, en el fondo la gente aún tiene presentes las modificaciones a la ley que se impulsaron en septiembre de 2019 y dieron lugar a la Comisión para la Erradicación de la Corrupción (CEC), lo que causó numerosas manifestaciones en las calles y peticiones por parte de defensores de la democracia. A los críticos les inquieta que las modificaciones, en virtud de las cuales se creó un comité compuesto por cinco personas que debe aprobar las actividades de la comisión, debilite drásticamente la efectividad de la CEC y su capacidad para perseguir los actos de corrupción. Desde su fundación en 2002, se ha aplaudido dentro y fuera de Indonesia la independencia de la CEC ante las intromisiones del gobierno y su capacidad de luchar contra la corrupción. Ahora, estos elementos de la CEC están en tela de juicio.

A pesar del posible debilitamiento de las medidas, los luchadores contra la corrupción tuvieron un motivo para celebrar cuando en agosto se aprehendió a dos generales de la policía que estaban bajo sospecha de haber aceptado sobornos. El Departamento de Investigación Criminal de la Policía Nacional (Bareskrim) aprehendió al inspector general Napoleón Bonaparte y al general brigadier Prasetyo Utomo, ambos acusados de aceptar sobornos de Djoko Tjandra para eliminar el nombre de este último de la lista de fugitivos más buscados de Interpol. Djoko cayó en Malasia en el mes de mayo, después de haber estado prófugo durante 11 años (Redaksi 2020).

Otra ley de 2019 que se cierne sobre 2020 es la Ley de Investigación y Tecnología, diseñada para dificultar significativamente el otorgamiento de permisos a investigadores y representantes de los medios de comunicación. Se prohíbe realizar investigaciones consideradas "de alto riesgo" o "peligrosas" para la "armonía de la sociedad o la seguridad 
nacional", o que pudieran dañar al Estado indonesio, incluyendo la investigación en "zonas de conflicto y prohibidas" (Undang-Undang 2019). Se ha aprehendido y deportado a académicos y periodistas desde la aprobación de la ley, lo que representa un retorno a la censura del acceso de extranjeros que se consideran críticos de Indonesia, característica del Nuevo Orden que también incluía la creación de listas negras.

Por último, una propuesta de legislación que prohíbe las conductas LGBTQ y las relaciones sexuales premaritales, promovida tanto por partidos islamistas como por conservadores, también asestaría un golpe a la democracia en un país que tradicionalmente ha sido conocido por su sociedad tolerante, aunque heteronormativa. Esto podría verse como otro elemento de la influencia creciente del islamismo en Indonesia, que se refleja en el número de "estatutos basados en la Sharía" que se han instaurado desde que inició el proceso de democratización. La iniciativa se suspendió en 2020, pero — de manera similar a lo que ocurre con la legislación sobre los Pancasila — podría volver a llevarse al Parlamento antes del término de su sesión en 2024.

\section{PAPÚA OCCIDENTAL: ${ }^{1}$ CONFLICTO CONTINUO, RESISTENCIA COORDINADA}

Las secuelas de las manifestaciones relativas a Papúa Occidental, que comenzaron en agosto de 2019, siguieron sintiéndose al año siguiente. Lo que comenzó como disturbios menores en dormitorios de una universidad en Surabaya, Java Oriental, se convirtió en protestas a nivel nacional contra el racismo en Indonesia, las cuales incluyeron a muchos habitantes que no eran papúes y contraprotestas hacia los papúes. Quedó de manifiesto el escandaloso racismo indonesio, cuando se llamó "perros", "monos” y "cerdos" a los papúes. Estudiantes javaneses y de otros orígenes, y más adelante grupos justicieros como el Frente de Defensores del Islam, un grupo islamista notablemente violento, y Pemuda Pancasila, un grupo vehementemente nacionalista que tiene vínculos con la delincuencia organizada, atacaron a

\footnotetext{
${ }^{1}$ En el anuario anterior, el informe sobre Indonesia hacía referencia a la provincia de "Irian Jaya". Este nombre no se ha empleado desde 1999, cuando la antigua provincia de Irian Jaya se dividió en dos y recibió los nombres de "Papúa" y "Papúa Occidental". El toponímico "Irian Jaya" se consideraba, y aún se considera, una invención del Nuevo Orden y un insulto a los residentes de la región. En el presente informe, el autor llama "Papúa Occidental" a ambas provincias, Papúa y Papúa Occidental, para simplificar y para reflejar el uso de los habitantes de la región.
} 
estudiantes de Papúa Occidental. Los recuentos de estas agresiones demuestran que las fuerzas de seguridad indonesias dirigieron las acciones y, en ocasiones posteriores, incluso participaron en la violencia contra los papúes.

En una maniobra decididamente antidemocrática, el gobierno indonesio implementó un apagón informativo en Papúa Occidental y desplegó a 10000 elementos de las fuerzas de seguridad en Papúa. Aunque se filtró información sobre las terribles agresiones en tiempo real, se dijo que estos reportes eran "embustes" diseñados para "diseminar el conflicto". Se detuvo y se agredió a periodistas en Papúa Occidental. En Java Occidental se aprehendió al periodista y cineasta indonesio Dandhy Laksono por publicar tuits en los que describía los hechos ocurridos en Papúa Occidental y expresaba su apoyo a la autodeterminación.

La policía indonesia arrestó a 56 personas y sigue realizando detenciones en Papúa y en otros sitios. Al momento en que se escribe el presente artículo, octubre de 2020, 107 presos políticos papúes siguen encarcelados, 25 de los cuales fueron liberados según una lista que compiló una organización de la sociedad civil que opera en Papúa. ${ }^{2}$ Algunos de estos presos han recibido sentencias de hasta 15 años de cárcel, incluyendo a líderes del Comité Nacional de Papúa Occidental. El director ejecutivo de Amnistía Internacional Indonesia afirmó que ha habido 47 ejecuciones extrajudiciales en Papúa desde febrero de 2018, así como otras violaciones graves a los derechos humanos (Devina Halim 2020). Un informe de la organización británica de derechos humanos TAPOL cita cifras más elevadas: 61 personas asesinadas, 284 lesionadas y casi 23000 desplazadas desde el levantamiento de agosto de 2019. El informe también menciona la total impunidad de la que gozaba la policía indonesia y que sólo a cinco soldados, a quienes se declaró culpables de abuso racial a los papúes, se les castigó con suspensiones temporales (Koman 2020).

En los medios masivos se sigue condenando a los papúes y a lo que se percibe como su "ingratitud" por la supuesta "generosidad" de Indonesia. Los artículos sobre las manifestaciones y la violencia citaban casi exclusivamente fuentes del gobierno, de la policía y militares que condenaban a los papúes. Se expresó muy poca empatía por su condición de pobreza y marginalidad y no se les permitió relatar su versión de los hechos. Como preguntó

\footnotetext{
${ }^{2} \mathrm{El}$ autor tuvo acceso a una lista detallada de aquellos que fueron aprehendidos, pero se le solicitó no nombrar su fuente para proteger al grupo.
} 
la escritora papú Tamara Soukotta, "si Papúa Occidental es, como afirma oficialmente el Estado indonesio, parte del Estado Unitario de la República de Indonesia, entonces ¿por qué se niegan los derechos constitucionales a los papúes occidentales, como ciudadanos de la República de Indonesia?” (Soukotta 2020).

Cuando se declaró la independencia de Indonesia, los holandeses no cedieron Papúa, que permaneció en sus manos hasta 1962, después de años de conflictos diplomáticos con Indonesia. Tras siete años y la transición del gobierno de Soekarno al de Suharto, Indonesia llevó a cabo un "Acto de elección libre" para determinar el futuro de la provincia, donde reinaba el descontento. Muchos consideran que esto fue una simulación, pues de una población de un millón de papúes, sólo votaron unos 1 200, además de que hubo numerosos homicidios y actos de intimidación y manipulación para alterar los resultados. Antes del acto surgió un movimiento separatista en Papúa, y los intentos de Indonesia por mejorar la situación después de la democratización de 1999, como el otorgamiento de una autonomía especial, han hecho muy poco por mitigar el descontento. La zona es muy rica en recursos, pero Papúa sigue siendo una de las provincias más pobres y con menor nivel educativo del país. El racismo flagrante de las manifestaciones de 2019 demuestra el desprecio que muchos indonesios sienten por los papúes, una prueba más del fracaso o la parcialidad de la soberanía indonesia.

A mediados de 2020 algunos activistas crearon el grupo Papuan Lives Matter [Las vidas papúes importan], inspirados por el movimiento Black Lives Matter [Las vidas negras importan] de Estados Unidos. Los manifestantes han reivindicado la palabra "mono", que se usaba peyorativamente en su contra, y se pintan el cuerpo con ella, tanto en indonesio como en inglés, durante las protestas. En septiembre, el ejército indonesio y los separatistas tuvieron un enfrentamiento en la región de Intan Jaya, que tuvo como resultado la muerte de un soldado. El 19 de septiembre, el pastor cristiano papú Yeremia Zanambani murió por un impacto de bala de las tropas indonesias, aunque éstas lo niegan. E1 26 de octubre, Rapinus Tigau, un catequista católico, también recibió un disparo y murió en Timika. Se dice que sus últimas palabras antes de que el ejército indonesio le disparara fueron: "Por favor, dejen de incendiar y de buscar, tenemos que hablar en calma". El ejército también le disparó a un niño de seis años en la cadera. Yeremia y Rapinusis son la tercera y la cuarta figuras religiosas a 
quienes se ha asesinado en Papúa desde 2000. En respuesta a la muerte de Yeremia, el Consejo de Iglesias de Papúa Occidental publicó una carta abierta dirigida a Jokowi en la que le recuerda que en 2019 prometió reunirse con papúes que estuvieran en pro del referendo y poner fin a la militarización creciente de la región, que se dio como respuesta a las manifestaciones y que incluyó el reclutamiento de mil soldados "de autonomía especial” por parte de Prabowo (The International Coalition for Papua 2020).

\section{Política INTERNACIONAL: CHINA MANTIENE EL PREDOMINIO}

China siguió siendo una presencia fundamental en las relaciones exteriores de Indonesia, que a su vez ha aplicado dos enfoques para lidiar con las repetidas incursiones chinas a las islas Natuna en el Mar de la China Meridional, localizadas dentro de la zona económica exclusiva de Indonesia. Al inicio de su primera administración, Jokowi criticó a China de manera abierta y repetida por la presencia de sus buques pesqueros en aguas indonesias. Incluso algunos de estos buques se remolcaron más cerca de Java y se hicieron explotar a manera de declaración. Pero, poco tiempo después, el gobierno de Jokowi restó importancia las incursiones chinas y tornó su atención a los buques invasores de Vietnam, Filipinas y otros países.

Una vez más, Indonesia está intentando solucionar con delicadeza las últimas incursiones, que se dieron en diciembre de 2019, mediante un enfoque de dos componentes. Jokowi envió barcos y aviones a Natuna para demostrar su fuerza después de sostener una reunión de gabinete en un buque de la Marina. Sin embargo, otros miembros de su gobierno, como Prabowo, han minimizado el tema retóricamente. Ejemplo de ello es el ministro coordinador de Asuntos Marítimos y de Inversiones, Luhut Pandjaitan, quien espera que la situación con China no empeore. "En realidad el tema es sencillo, no es necesario hacerlo más grande”, afirmó Luhut. “¿Por qué pelear por algo que no debe ser un problema?” (Christy 2020).

Frente a las continuas afirmaciones de soberanía china en el Mar de la China Meridional, incluyendo el territorio que reclama, es probable que Indonesia fortalezca sus relaciones con la Asociación de Naciones del Sudeste Asiático (ASEAN, por sus siglas en 
inglés), pero también con Australia y Estados Unidos. Dado que el futuro del abordaje de Estados Unidos a la política internacional se decidirá en las elecciones de noviembre Trump y su "diplomacia transaccional" o la vuelta a la habilidad política tradicional estadunidense, que incluye la creación de alianzas y el intento de ser un contrapeso de China—, quizá Jokowi esté esperando el momento oportuno para hacer avances más claros.

Los reportes que se hicieron en marzo en el sentido de que Indonesia cancelaría la compra de aviones caza Sukhoi, de fabricación rusa, debido a presiones del gobierno de Trump, resultaron ser prematuros (Salna y Arys 2020). El secretario de la Defensa Prabowo fue a Rusia en junio para las celebraciones del Día de la Victoria y discutió la compra con sus contrapartes rusos durante la visita. Parte del trato depende de que Indonesia realice una porción de su pago en commodities, como caucho, café y aceite de palma, pero la fluctuación de sus precios ha alargado las negociaciones. Además, Indonesia está pensando en comprar otros equipos y aviones militares a Rusia, aunque también considera la opción de comprar aviones OSPREY F-35 y MV-22 a Estados Unidos (Ronna Nirmala 2020). El 15 de junio hubo un accidente en Riau con un avión Hawk 209, cuyo piloto logró con seguridad eyectar su asiento, lo que recalcó la importancia de actualizar y dar mantenimiento a la Fuerza Aérea indonesia. Sin embargo, 11 días antes fallecieron cinco personas cuando se accidentó un helicóptero Mi-17 de la Fuerza Aérea. La estrategia de Indonesia de comprar aviones y helicópteros provenientes de varios países ha hecho que surjan cuestionamientos sobre la integración del equipamiento. El país lanzó dos nuevos buques patrulleros rápidos en agosto, en el marco de su plan para proteger sus aguas territoriales; además está actualizando la fragata ligera KRI Usman-Harun, que está envejeciendo.

Indonesia sigue participando en la política internacional orientada al islam, buscando mantener su papel en este ámbito. Por ejemplo, tras los sucesos de violencia religiosa que se dieron en India, Jokowi convocó al embajador indio para que diera una explicación al respecto. La crisis con los rohingya en Myanmar (Birmania) es otro tema. Aunque Indonesia ha tratado de equilibrar las inquietudes por los derechos humanos y la recepción de refugiados rohingya y su relación con Myanmar, la presión interna por parte de grupos de orientación islamista por "defender al islam" hizo que el país tomara una posición de mayor aceptación. Estas presiones permanecen, aunque Indonesia ha guardado un silencio relativo 
en cuanto al terrible trato que se da a la etnia Uighur en China, lo que quizá refleja el poder y la influencia de esta última. Sin embargo, las afirmaciones de que la política exterior Indonesia se está "islamizando" (Nagda 2020), pueden reflejar islamofobia o un recuento ahistórico de la relación entre el islam y la política desde el inicio de la democratización.

En relación con la ASEAN, la adopción en 2019 de la "Centralidad de la ASEAN” y la "Perspectiva de la ASEAN sobre el Indo-Pacífico" (AOIP, por sus siglas en inglés) significa que, en tanto Estado miembro, Indonesia tendrá que equilibrar sus relaciones bilaterales con Estados Unidos y con China en virtud de la relación que guarda con esa asociación. Unirse a Estados Unidos contra China podría tener algunas ventajas para el bloque de la ASEAN, pero también podría tenerlas el seguir una vía intermedia. Sin embargo, la ASEAN se arriesgaría a confrontar a China si decidiera seguir la propuesta del Indo-Pacífico Libre y Abierto (FOIP, por sus siglas en inglés) del Diálogo de Seguridad Cuadrilateral (también conocido como the Quad), que encabezan Estados Unidos, India, Japón y Australia (Sulaemon 2020). Es probable que la ASEAN mantenga un involucramiento tibio con el Quad. No obstante, mucho depende de los movimientos que haga China en el Mar de la China Meridional, y si actuara con mayor belicosidad, ello empujaría a las naciones de la ASEAN y a Estados Unidos a responder. Por tanto, es posible que la política de la ASEAN y de Indonesia sea reactiva. De cualquier manera, como promotora de la AOIP, Indonesia ha asumido un papel de liderazgo respecto de este tema en el seno de la ASEAN y seguirá asumiéndolo.

\section{DESASTRES NATURALES Y FALLECIMIENTOS NOTABLES}

El $1^{\circ}$ de enero cayeron lluvias torrenciales y, por lo tanto, se produjeron inundaciones en Yakarta y Java Occidental que causaron decenas de muertes y decenas de miles de desplazamientos. Un evento posterior, a fines de febrero, provocó que muchas más decenas de miles tuvieran que evacuar sus hogares. En septiembre hubo más inundaciones en Yakarta y Java Occidental que causaron el desplazamiento de otros miles de personas. De acuerdo con el Badan Nasional Penanggulan Bencana (el Consejo Nacional para la Gestión de Desastres), ha habido más de mil inundaciones y deslaves a septiembre de 2020, un año especialmente malo en este sentido. 
Sin embargo, no sólo el agua ha hecho estragos en Indonesia, sino también el fuego. Anak Krakatau, el "hijo" del famoso volcán Krakatau que hizo erupción en 1883 y mató a decenas de miles de personas, tuvo una erupción menor en el mes de abril. Se unieron a él, ¡el mismo día! otros tres volcanes: el Monte Kerinci en Sumatra Occidental, el Monte Semeru en Java Oriental y el Monte Merapi en Java Central, todos los cuales mostraron actividad elevada. Los vulcanólogos afirmaron que las erupciones simultáneas fueron una mera coincidencia.

El 25 de marzo, en Surakarta, Java Central, la madre de Jokowi, Sujiatmi Notomihardjo, falleció tras una batalla de cuatro años contra el cáncer de laringe. Además, el 23 de abril falleció Arief Budiman, sociólogo egresado de la Universidad de Harvard, activista y aguerrido crítico del régimen de Suharto. Fue profesor en la Universidad Cristiana de Satya Wacana en Java Central, pero se le despidió en 1996 por presiones del ejército indonesio. Posteriormente, pasó varios años en la universidad de Melbourne, Australia, y volvió a Salatiga tras su retiro en 2008. Aunque pagó el precio de su activismo por enfrentarse a la dictadura, nunca guardó silencio y su muerte es una gran pérdida para Indonesia, tanto en el ámbito intelectual como en el social.

Traducción: María Capetillo Lozano

Chris Lundry es profesor investigador en el Centro de Estudios de Asia y África de El Colegio de México. Su investigación se centra en Indonesia y Timor Oriental, así como en el sureste asiático en general, con temas que incluyen la democratización, el conflicto, la reconciliación, la religión y la política. Obtuvo su doctorado por la Universidad Estatal de Arizona en 2009 y llegó al Colegio de México proveniente de la ASU en 2017.

clundry@,colmex.mx

\section{REFERENCIAS}

Abdul Rochim. 2020. "Polemik RUU HIP, PBNU Tegaskan Pancasila Sudah Final." SINDOnews.com, junio 16, 2020. https://nasional.sindonews.com/read/71538/12/ polemik-ruu-hip-pbnu-tegaskan-pancasila-sudah-final-1592298374 
Budi Purwanto. 2020. "Ghosts' scare Indonesians indoors and away from coronavirus." Yahoo! News, abril 13, 2020. https:/www.yahoo.com/news/ghosts-scareindonesians-indoors-away-064116967.html

Busby, Joshua. 2020. 'Indonesia's half-hearted response to Covid-19: the role of politics and historical legacies." The Duck of Minerva, agosto 4, 2020. https://duckofminerva. com/2020/08/indonesias-half-hearted-response-to-covid-19-the-role-of-politics-andhistorical-legacies.html

Christy, Francisca. 2020. "Natuna Waters Issue, Prabowo: China is a Friend Country." Traducido por Mahinda Arkyasa. Tempo, enero 4, 2020. https://en.tempo.co/read/ 1291080/natuna-waters-issue-prabowo-china-is-a-friend-country

CNN Indonesia. 2020. "Canda wapres sebut susu kuda liar bisa tangkal Virus Corona.” CNN Indonesia, marzo 3, 2020. https://www.cnnindonesia.com/nasional/2020031117024120-482556/canda-wapres-sebut-susu-kuda-liar-bisa-tangkal-virus-corona

Detiktravel. 2020. “Gubernur Bali: Terapi Arak Bali Efektif Sembuhkan OTG Corona.” Detiktravel, julio 23, 2020. https://travel.detik.com/travel-news/d-5104762/ gubernur-bali-terapi-arak-bali-efektif-sembuhkan-otg-corona

Devina Halim. 2020. “Amnesty: Ada 47 Pembunuhan di Luar Proses Hukum di Papua Sejak 2018." Kompas.com, septiembre 28, 2020. https://nasional.kompas.com/read/2020/ 09/28/22153291/amnesty-ada-47-pembunuhan-di-luar-proses-hukum-di-papua$\underline{\text { sejak-2018 }}$

Honna, Jun. 2020. "Military Politics in Pandemic Indonesia." Asia Pacific Journal 18 (15). https://apjjf.org/-Jun-Honna/5439/article.pdf

Ihsan Ali Fauzi. 2020. "Pelibatan TNI dalam Soal Kerukunan Beragama Mengkhianati Reformasi." Tirto.id, julio 7, 2020. https://tirto.id/pelibatan-tni-dalam-soalkerukunan-beragama-mengkhianati-reformasi-fNY9

Imam Rosidin. 2020. “4.000 Lebih Turis China Masih Tercatat Masuk Bali pada Februari 2020." Kompas, marzo 4, 2020. https://denpasar.kompas.com/read/2020/03/04/ 16364241/4000-lebih-turis-china-masih-tercatat-masuk-bali-pada-februari-2020 
Kine, Phelim. 2020. “Indonesia's New Omnibus Law Trades 'Green Growth' for Environmental Ruin.” The Diplomat, octubre 14, 2020. https://thediplomat.com/ 2020/10/indonesias-new-omnibus-law-trades-green-growth-for-environmental-ruin/

Koman, Veronica. 2020. The 2019 West Papua Uprising: Protests Against Racism and for Self-Determination. TAPOL, septiembre 2020. https://www.tapol.org/sites/default/ files/The 2019 West Papua Uprising.pdf

Mahfira Putra Maulani. 2020. “Ancaman Bupati Sragen: Pemudik dan ODP Corona Tak Tertib Bakal Dikarantina di Gedung Kosong Berhantu.” Tribun Jateng, abril 17, 2020. https://jateng.tribunnews.com/2020/04/17/ancaman-bupati-sragen-pemudikdan-odp-corona-tak-tertib-bakal-dikarantina-di-gedung-kosong-berhantu?page=all

Nagda, Ashutosh. 2020. "The Islamization of Indonesia's Foreign Policy." The Diplomat, marzo 7, 2020. https://thediplomat.com/2020/03/the-islamization-of-indonesiasforeign-policy/

Parameswaran, Prashanth. 2020. 'Interview: Indonesian Politics During Jokowi’s Second Term.” The Diplomat, marzo 10, 2020. https://thediplomat.com/2020/03/interviewindonesian-politics-during-jokowis-second-term

Redaksi, Tim. 2020. "Dua Jenderal Polri Jadi Tersangka Red Notice Djoko Tjandra.” Voice of Indonesia, agosto 14, 2020. https://voi.id/berita/11312/dua-jenderal-polri-jaditersangka-i-red-notice-i-djoko-tjandra

Reuters Staff. 2020. “Global investors raise environmental concerns over Indonesia jobs bill." Reuters, octubre 5, 2020. https://www.reuters.com/article/indonesia-economylaw-investors/global-investors-raise-environmental-concerns-over-indonesia-jobsbill-idUSL1N2GW07M

Ronna Nirmala. 2020. "Russia: Deal to Sell Indonesia Sukhoi Fighter Jets Still Stands." Benar News, agosto 7, 2020. https://www.benarnews.org/english/news/indonesian/ Russian-fighter-jets-07082020162231.html

Rosyid, Tony. 2020. “Benarkah KH Ma’ruf Amin Akan Diganti?” Cakrawarta.com, agosto 10, 2020. http://www.cakrawarta.com/benarkah-kh-maruf-amin-akan-diganti.html 
Salna, Karlis y Arys Aditnya. 2020. "Trump threat spurred Indonesia to drop Russia, China arms deals." The Jakarta Post, marzo 13, 2020. https://www.thejakartapost.com/ news/2020/03/13/trump-threat-spurred-indonesia-to-drop-russia-china-armsdeals.html

SBS News. 2020. "Anti-maskers in Indonesia have been forced to dig graves for coronavirus victims as punishment.” SBS News, septiembre 15, 2020. https://www.sbs.com.au/ news/anti-maskers-in-indonesia-have-been-forced-to-dig-graves-for-coronavirusvictims-as-punishment

Soukotta, Tamara. 2020. "An uprising in Papua." Jacobin, septiembre 23, 2020. https://www.jacobinmag.com/2019/09/protests-west-papua-indonesia-surabaya$\underline{\text { attack }}$

Sulaemon, Fadhil Haedar. 2020. "ASEAN, the Quad, and China: a security contestation for the Indo-Pacific region.” ASEAN Studies Center-Universitas Gadjah Mada, Faculty of Social and Political Sciences, abril 20, 2020. https://asc.fisipol.ugm.ac.id/2020/04/20/ asean-the-quad-and-china-a-security-contestation-for-the-indo-pacific-region/

The Economist. 2020. "How not to reform Indonesia." The Economist, octubre 17, 2020. https://www.economist.com/asia/2020/10/15/how-not-to-reform-indonesia

The International Coalition for Papua. 2020. "West Papua Council of Churches demands the Govt to stop the remilitarization of Papua." The International Coalition for Papua Human Rights and Peace for Papua, octubre 9, 2020. https://www.humanrightspapua. org/news/32-2020/669-council-of-churches-demand-the-govt-to-stop-theremilitarisation-of-papua

The Jakarta Post. 2020. "Central Lombok to require female Muslim civil servants to wear niqab in place of mask." The Jakarta Post, julio 2, 2020. https://www.thejakartapost. com/news/2020/07/02/central-lombok-to-require-female-muslim-civil-servants-towear-niqabin-place-of-mask.html

Timmerman, Antonia. 2020. “Omnibus Law: Indonesian police launch 'cyber patrols' as protesters coordinate mass action." South China Morning Post, octubre 6, 2020. 
https://www.scmp.com/week-asia/politics/article/3104412/indonesians-beginprotests-against-omnibus-jobs-law-amid-online

Tri Bayu Purnama, Siti Khodijah e Idris Sadri. 2020. "How to handle the deceased body of Covid-19: an insight from Indonesian muslim burial handlers' knowledge, perception and practice." medRxiv, agosto 7, 2020. https://www.medrxiv.org/content/10.1101/ 2020.08.03.20167593v1

Undang-Undang Republik Indonesia. Nomor 11 Tahun. 2019. Tentang Sistem Nasional Ilmu Pengetahuan Dan Teknologi. https://peraturan.bpk.go.id/Home/Download/107926/ UU\%20Nomor\%2011\%20Tahun\%202019.pdf

Walden, Max y Hellena Souisa. 2020. "Why are so many Indonesian children dying from coronavirus?" $A B C$ News, junio 17, 2020. https:/www.abc.net.au/news/2020-0618/why-are-so-many-indonesian-children-dying-from-coronavirus/12356444

Wartakotalive.com. 2020. "Menteri Pertanian Klaim Kalung Kayu Putih Ampuh Bunuh Covid-19 dalam 30 Menit”. https://wartakota.tribunnews.com/2020/07/05/menteripertanian-klaim-kalung-kayu-putih-ampuh-bunuh-covid-19-dalam-30-menit

Woodward, Mark. 2020. "Nahdlatul Ulama, pesantren, and the pandemic.” Inside Indonesia, abril 23, 2020. https://www.insideindonesia.org/nahdlatul-ulama-pesantren-and-thepandemic 